\title{
Attenuation of global ultraviolet and visible irradiance over Greece during the total solar eclipse of 29 March 2006
}

\author{
A. Kazantzidis ${ }^{1}$, A. F. Bais ${ }^{1}$, C. Emde $^{2}$, S. Kazadzis ${ }^{1}$, and C. S. Zerefos ${ }^{3}$ \\ ${ }^{1}$ Laboratory of Atmospheric Physics, Aristotle University of Thessaloniki, Thessaloniki, Greece \\ ${ }^{2}$ Institut für Physik der Atmosphäre, Deutsches Zentrum für Luft- und Raumfahrt (DLR), Oberpfaffenhofen, 82234 Wessling, \\ Germany \\ ${ }^{3}$ National Observatory of Athens, Athens, Greece
}

Received: 7 August 2007 - Published in Atmos. Chem. Phys. Discuss.: 14 September 2007

Revised: 26 November 2007 - Accepted: 26 November 2007 - Published: 6 December 2007

\begin{abstract}
The variability of ultraviolet and photosynthetically active radiation (PAR) during the total solar eclipse of 29 March 2006 was examined in this study. The measurements from NILU-UV multichannel radiometers at 7 stations of the Greek UV Network were used, where the maximum eclipse percentage ranged from $73.1 \%$ to $94.8 \%$. In addition, an extra instrument was established at a remote Greek island, Kastelorizo, which was within the Moon's umbral shadow. The reduction of irradiance at 305 and $312 \mathrm{~nm}$ relative to non-eclipse conditions at all sites was almost 1.5 times more than the corresponding decrease in the UVA and visible part of the spectrum and reached $98 \%$ for eclipse percentage equal to $94 \%$. The availability of several instruments in close proximity to the path of the umbral shadow provided a challenging test for the models. The measured changes in UV and visible irradiance were compared with 1-D model calculations accounting for the limb darkening effect. The agreement between measurements and modeled values at all sites is within 3\% for eclipse percentages of less than $30 \%$ and becomes worse as the eclipse progresses. The 1-D model reproduced the spectral effect of the eclipse in UVA and PAR wavelength regions within $3 \%$ for eclipse percentages up to $50 \%$, but only the half of the observed change was captured as the eclipse progressed. At three sites, where the eclipse maximum was more than $94 \%$, the measured irradiance at $305 \mathrm{~nm}$ for eclipse percentages of more than $85 \%$ decreased with slower rates than for longer wavelengths. As a result, the total ozone values, derived from the $305 / 320 \mathrm{~nm}$ ratios, apparently decreased significantly for high eclipse percentages. The effect is similar at all three sites, but the interpretation of this observation remains a challenge. Comparison results with 3-D model calculations shortly before, during and shortly after totality were performed for the first time and revealed an agreement with measurements within $20 \%$ in the
\end{abstract}

Correspondence to: A. Kazantzidis

(akaza@auth.gr)
UV-A region. However, the modeled estimates of irradiance at $312 \mathrm{~nm}$ are three times lower than measured values.

\section{Introduction}

The variability of surface solar irradiance during a solar eclipse due to the change in atmospheric conditions and the limb darkening effect has been extensively investigated (e.g. Sharp et al., 1971; Silverman and Mullen, 1975; Fernadez et al., 1991; Mikhalev et., 1999; Zerefos et al., 2000 and 2001; Koepke et al., 2001). Sharp et al. (1971) presented a selected group of sky brightness measurements during total solar eclipses. They reported that although the brightness could be represented with reasonable accuracy for solar eclipse percentages up to $99.8 \%$, the effect of multiple scattering from outside the umbral region dominate the sky brightness during totality. Mikhalev et al. (1999) suggested that the variability of ultraviolet irradiance close to the maximum of the eclipse is caused by an increase in the share of the multiply scattered radiation. Zerefos et al. (2000) reported that the rate of decline in the diffuse irradiance is slower than in the direct irradiance as the eclipse progresses. This effect is more pronounced at shorter wavelengths and could be explained by the contribution of multiple scattering radiation originating from surrounding areas that are shadowed less than the location where the measurements are conducted. Kazadzis et al., 2007, concluded that global and direct irradiance measurements were spectrally affected by the limb darkening during the eclipse, leading to wavelength dependent changes in the measured solar spectra.

The spectral variability of solar irradiance stimulated the development of methods and algorithms in order to simulate this effect. Shaw et al. (1978) developed a simplified radiative transfer model for estimating the brightness, or the radiance, of the sky during a total solar eclipse and predicted

Published by Copernicus Publications on behalf of the European Geosciences Union. 
Table 1. The geographical position, times of the beginning, maximum and end of the eclipse and the maximum percentage coverage of the Sun at the stations of the Greek UV network.

\begin{tabular}{llllllll}
\hline $\begin{array}{l}\text { Station } \\
\text { number }\end{array}$ & $\begin{array}{l}\text { Station } \\
\text { name }\end{array}$ & $\begin{array}{l}\text { Latitude } \\
\left({ }^{\circ} \mathrm{N}\right)\end{array}$ & $\begin{array}{l}\text { Longitude } \\
\left({ }^{\circ} \mathrm{E}\right)\end{array}$ & $\begin{array}{l}\text { Start of } \\
\text { eclipse }\end{array}$ & $\begin{array}{l}\text { Maximum } \\
\text { of eclipse }\end{array}$ & $\begin{array}{l}\text { End of } \\
\text { eclipse }\end{array}$ & $\begin{array}{l}\text { Maximum obscuration } \\
\text { of solar disk }(\%)\end{array}$ \\
\hline 1 & Ioannina & 39.62 & 20.85 & $09: 30$ & $10: 45$ & $12: 00$ & 73.1 \\
2 & Thessaloniki & 40.63 & 22.96 & $09: 34$ & $10: 49$ & $12: 04$ & 75.1 \\
3 & Patra & 38.29 & 21.79 & $09: 28$ & $10: 45$ & $12: 01$ & 78.7 \\
4 & Athens & 37.99 & 23.77 & $09: 30$ & $10: 47$ & $12: 04$ & 84 \\
5 & Mytilene & 39.11 & 26.55 & $09: 35$ & $10: 53$ & $12: 09$ & 87 \\
6 & Heraklion & 35.31 & 25.08 & $09: 27$ & $10: 46$ & $12: 10$ & 94.3 \\
7 & Nicosia & 35.18 & 33.38 & $09: 37$ & $10: 58$ & $12: 15$ & 94.8 \\
8 & Kastelorizo & 36.15 & 29.60 & $09: 34$ & $10: 53: 28$ & $12: 11$ & 100 \\
\hline
\end{tabular}

quite well the major observed features of the sky under the eclipse. More recently, Koepke et al. (2001) modeled the spectral variation of the extraterrestrial solar flux during a solar eclipse taking into account the limb darkening effect and concluded that this effect reaches a maximum of $30 \%$ at $1500 \mathrm{~nm}$, and of $60 \%$ at $310 \mathrm{~nm}$. The modified extraterrestrial spectrum was used in a 1-D radiative transfer model and the results were in good agreement when compared with measured radiation quantities. Much more accurate results were reported by Emde and Mayer (2007). They used a backward 3-D Monte Carlo method in order to simulate the effect of multiple scattering on irradiance and radiance in the umbral shadow. They reported that, compared with 1-D model results, the irradiance is larger in the 3-D calculations because of more accurate treatment of multiple scattering. Using the atmospheric and eclipse conditions at the Kastelorizo, Greece, in the Eastern Mediterranean, they concluded that $10 \mathrm{~min}$ ahead and after the totality the relative difference between the two models is less than $1 \%$.

The uncertainties associated with the characterization of the radiation field during a solar eclipse, especially in the shorter UV-B wavelengths, and those associated with changes in the atmospheric conditions, especially with respect to ozone, resulted in different and sometimes contradicting conclusions on the effects of the eclipse on the ozone column (e.g. Bojkov, 1968, Mariolopoulos et al., 1977; Mim and Mims, 1993; Chakrabarty et al., 1997 and 2001; Zerefos et al., 2000; Winkler et al., 2001). Measurements with a Dobson spectrophotometer revealed either increase (e.g. Bojkov, 1966) or decrease (Chakrabarty et al., 1997) of total ozone during the eclipse. Zerefos et al. (2000) investigated the changes in the ozone column measurements with Brewer and Dobson spectroradiometers from six European sites during the solar eclipse of 11 August 1999. In all cases, the observed increase in the measured total ozone by more than $10 \%$ close to the eclipse maximum was considered as artificial, attributed to the increasing contribution of the diffuse radiation during the course of the eclipse. Similar results were reported also Kazadzis et al. (2007). Winkler et al. (2001) reported contradicting results from Brewer and Microtops ozone measurements at Hohenpeissenberg during the total solar eclipse of 11 August 1999. Chakrabarty et al. (2001) suggested that the observed ozone variability over India during the eclipse of 24 October 1995 could not be explained by the variations in the rates of conventional photochemical and dynamical processes or by the formation of gravity waves during the eclipse.

In this study, measurements from multi channel radiometers comprising the Greek UV monitoring network were used to investigate the variability of the ultraviolet and the photosynthetically active radiation (PAR) during the total solar eclipse of 29 March 2006. The availability of several instruments in close proximity of the umbral shadow, compared to earlier studies, is a novelty and the existence of good weather conditions provide a unique opportunity to test 1-D and 3-D model results. The measurements were compared with 1-D model estimates for the duration of the eclipse except from the period close and during the totality and with 3-D model estimates during the totality. Finally, the variations in global UV and visible irradiance and in the ozone column derived from the multi channel radiometers during the eclipse are presented and discussed for the first time.

\section{Instrumentation and data}

The Greek UV monitoring network was designed to cover geographically Greece and Cyprus, with nine stations distributed at locations with different environments. At the central station, located in Thessaloniki, a suite of spectral and broadband radiation and other related measurements are also available. The network is equipped with NILU-UV multichannel radiometers, providing UV irradiance measurements at five wavelength bands centered at 305, 312, 320, 340 and $380 \mathrm{~nm}$, with full width at half maximum (FWHM) of approximately $10 \mathrm{~nm}$. A sixth channel is used for the measurement of photosynthetic active radiation between 400- 


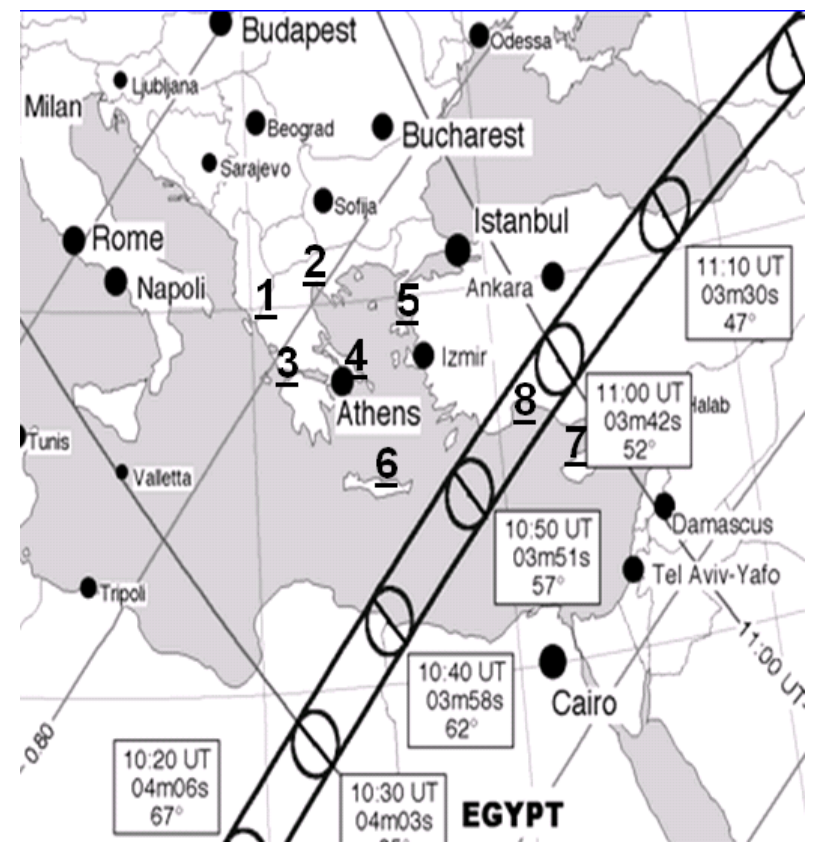

Fig. 1. Eclipse map and ground based stations (numbers 1-8, according to Table 1). The eclipse map is provided by NASA, Goddard Space Flight Center (http://sunearth.gsfc.nasa.gov/eclipse/ SEmono/TSE2006/TSE2006.html)

$700 \mathrm{~nm}$. Technical details for these instruments can be found in Hoiskar et al. (2001). Before the deployment of the instruments at the different sites, all channels were characterized as to their spectral response with a powerful $1000 \mathrm{~W}$ xenon lamp and a double monochromator. Following the deconvolution procedure suggested by Bernhard et al. (2005), the calibration factors to convert the measured signals to spectral irradiance at the central wavelength of each channel were calculated. The absolute calibration factors were determined by comparison to the spectral irradiance measurements from a double monochromator Brewer spectroradiometer \#086, operating at Thessaloniki, according to the methodology described in Dahlback (1996). According to Bernhard (2005) the agreement with spectral measurements is within $\pm 5 \%$ for solar zenith angles smaller than $85^{\circ}$.

In March 2006, only seven of the stations were in operation. At these stations the maximum of the eclipse percentage ranged from $73.1 \%$ to $94.8 \%$ (see Table 1). An extra station was established as part of a two-day experimental campaign at the Greek island of Kastelorizo (Kazadzis et al., 2007), which was located inside the track of the total eclipse of 29 March 2006. The geographical positions of all stations, as well as the path of the Moon's umbral shadow, are shown in Fig. 1. All stations are located at altitudes below $200 \mathrm{~m}$ except from Ioannina, which is located $500 \mathrm{~m}$ a.s.l.

During the day of the eclipse all instruments were sampled every second and the data were recorded at this fre-
Table 2. Cloud conditions at the ground-based stations, derived from observations at the sites or at nearby meteorological stations, close to the maximum time of the solar eclipse.

\begin{tabular}{|c|c|c|}
\hline $\begin{array}{l}\text { Station } \\
\text { number }\end{array}$ & $\begin{array}{l}\text { Station } \\
\text { name }\end{array}$ & $\begin{array}{l}\text { Cloud conditions close } \\
\text { to the eclipse maximum time }\end{array}$ \\
\hline 1 & Ioannina & Scattered cumulus \\
\hline 2 & Thessaloniki & Few cumulus, broken cirrus \\
\hline 3 & Patra & Few cumulus \\
\hline 4 & Athens & Few cumulus, broken cirrus \\
\hline 5 & Mytilene & Few cumulus, broken cirrus \\
\hline 6 & Heraklion & Few cumulus, scattered cirrus \\
\hline 7 & Nicosia & Few cumulus \\
\hline 8 & Kastelorizo & Few cumulus, scattered cirrus \\
\hline
\end{tabular}

quency, while regularly their measurements are recorded as one-minute averages. The original, high frequency, measurements were used only in studying the effect of the eclipse during totality at Kastelorizo. One-minute averages have been calculated and used in all other cases, for the purpose of comparison with measurements in previous days. The irradiance measurements at all sites during the period of the eclipse correspond to solar zenith angles ranging between $31^{\circ}$ and $44^{\circ}$. Under such conditions, the angular response error of the instruments could be considered within 3\% for all NILU-UV channels (Kazantzidis et al., 2006).

Absolutely calibrated irradiance measurements at 305 and $320 \mathrm{~nm}$ were used only for deriving total ozone, following the methodology described by Dahlback (1996), using oneminute averages of the irradiance ratios $305 / 320 \mathrm{~nm}$. According to Dahlback (1996), the relative difference in derived ozone abundance is $0.3 \pm 1.9 \%$ for clear skies and solar zenith angles less than $60^{\circ}$. Irradiance measurements below 10 times the dark signal have not been used in order to minimize the noise in the retrieved ozone columns. The spatial and temporal range of ozone across all stations during the eclipse was between 285 and 355 D.U.

Clouds interfere with the irradiance measurements, as to certain extend they mask the effects of the eclipse, and complicate the interpretation of the measurements. In Thessaloniki and Kastelorizo the cloud observations were conducted by the operators of the instruments, while at all other stations the meteorological reports from the nearby airports were used. These reports are made every 30 or $60 \mathrm{~min}$, thus they are not fully representative of the cloud conditions that may change between observations. In none of the sites the sky was clear during the eclipse. Few (1-2 octas) or scattered (3-4 octas) cumulus clouds have been reported for most of the time, and occasionally, especially during the second phase of the eclipse, scattered or broken (5-7 octas) cirrus clouds. Table 2 summarizes for all sites the cloud conditions close to the eclipse maximum. 


\section{Narrowband irradiance measurements and model calculations}

\subsection{Irradiance measurements}

The change in surface irradiance during the eclipse at different wavelengths is investigated using the irradiance data from the NILU-UV radiometers. To eliminate changes that have been introduced by the changing solar zenith angle during the eclipse, we normalized the irradiance measurements with measurements during the closest to the eclipse cloudfree day. The closest cloud-free days for all stations were found between 27 March and 2 April, thus we matched the measurements in the two days with respect to the time of the measurements and not with respect to SZA. The maximum change in the solar zenith angle for the same time between these consecutive days is less than $1.2^{\circ}$ and the corresponding model calculated cloud-free difference in channel irradiance is $2.1 \%$ at $305 \mathrm{~nm}, 1.4 \%$ at $312 \mathrm{~nm}$ and less than $1 \%$ at all other NILU-UV channels. Assuming that the instruments' sensitivity remained stable during such a short period, the cloud-free normalization ratios were formed from the raw data, after removal of the dark signal.

The ratios of raw counts at the selected days vary among stations by up to $9 \%$ at $380 \mathrm{~nm}$, and up to $25 \%$ at $305 \mathrm{~nm}$. These differences are attributable to changes in the cloud cover, aerosol abundance and, for the UV-B channels, in addition to changes in the ozone column. Measurements of the aerosol optical depth were available only at Thessaloniki and Kastelorizo, while total ozone was available at all sites. Generally, the total ozone differences between the day of the eclipse and the corresponding cloud-free day for each site were less than $15 \%$. Model calculations for a typical total ozone column (330 D.U.) and aerosol optical depth (0.4 at $340 \mathrm{~nm}$ ) showed that the effect of a $15 \%$ difference in total ozone on the irradiance at 305,312 and $320 \mathrm{~nm}$ is respectively $10 \%, 1 \%$ and $0 \%$, for the range of the solar zenith angles during the period of the eclipse $\left(31^{\circ}\right.$ to $\left.44^{\circ}\right)$.

The ratios of raw counts were then normalized with their corresponding average over the cloud-free $5 \mathrm{~min}$ period closest to the beginning of the eclipse. Thus all ratios are brought to the same scale, allowing direct comparisons between different channels. The normalization reduces partly the effect of the changes in total ozone between the two days; therefore at the shorter wavelengths ozone variations during the day are still influencing the irradiance.

\subsection{Model calculations}

Irradiance calculations in the UV and visible part of the spectrum during the eclipse were performed with the UVSPEC radiative transfer model (Mayer and Kylling, 2005). The radiative transfer equation is solved using the pseudo-spherical discrete ordinates algorithm (Dahlback and Stamnes, 1991) running with 16 streams and the spectral irradiance was cal- culated under cloud-free conditions from 280 up to $700 \mathrm{~nm}$ with $1 \mathrm{~nm}$ steps and resolution. The uncertainty in computed spectral irradiance is estimated to within $2 \%$ for cases with small solar zenith angles (van Weele et al., 2000). The vertical profile of aerosols by Elterman (1979) was scaled to the aerosol optical depth of 0.4 at $340 \mathrm{~nm}$, and an Angstrom exponent of 1.3 was used for its spectral dependence. These values are typical for Thessaloniki (Kazadzis et al., 2006) and eastern Mediterranean (e.g. Kalivitis et al., 2007). The same aerosol optical depth was measured at Kastelorizo on the day of the eclipse (Kazadzis et al., 2007). A doubling of the aerosol optical depth at $340 \mathrm{~nm}$ from 0.4 to 0.8 for the largest solar zenith angle during the eclipse $\left(44^{\circ}\right)$ and the highest measured total ozone (355 D.U.) would result in a decrease in the modeled irradiance by $15 \%$ at $305 \mathrm{~nm}$, down to $6 \%$ for PAR. The corresponding effect on the spectral ratios would have been between $-4.5 \%$ (for the ratio $305 / 380 \mathrm{~nm}$ ) and $5 \%$ (for the ratio of PAR/380 nm). Finally, the effect on the calculation of total ozone from the irradiance would have been about $1.4 \%$.

Typical values for the aerosol single scattering albedo $(\omega=0.95)$ and the asymmetry factor $(g=0.7)$ were used for all wavelengths and were assumed constant with altitude. AFGL midlatitude winter vertical profiles for air density, ozone and temperature were used (Anderson et al., 1986) and the surface albedo was set to 0.05 , independent of wavelength. The Atlas-3 spectrum was chosen as the extraterrestrial solar flux (van Hoosier, 1996). The modification of solar extraterrestrial irradiance due to the coverage of the solar disk was calculated by the formulas adapted from Koepke et al. (2001). These formulas provide the relative effect of the eclipse on each wavelength in the UV and visible regions for eclipse percentage up to $99 \%$.

In order to compare model calculations with measurements, the calculated spectra were convoluted with a generic spectral response for each channel. The effect of the differences among the spectral responses of the instruments was estimated to less than $1 \%$. Then, the spectral irradiances were normalized with the calculated irradiances for non-eclipse conditions. A sensitivity study on modeled convoluted spectra (using the real and not a generic response for each instrument) revealed that the normalized channel ratios were independent (less than $0.05 \%$ difference) for all solar zenith angles ( 31 to $44^{\circ}$ ) and measured total ozone abundances (285 to 355 D.U.) during the eclipse of 29 March.

\section{Effect of solar eclipse on surface solar irradiance}

The decrease in spectral irradiance during the eclipse was examined for all NILU-UV channels. The data from sites 6 through 8 are presented together because of higher percentages of eclipse and better exposure conditions, due to reduced cloudiness. In the following we present changes in the irradiance ratios as a function of the percentage of the visible 
part of the solar disk, according to the formulas described in Espenak and Anderson (2004). The value of 0 corresponds to the totality of the eclipse, while the values of -100 and +100 correspond to the beginning and the end of the eclipse, respectively.

\subsection{UV-B irradiance}

Figure 2 shows the change in spectral solar irradiance at $305 \mathrm{~nm}$, which appears to vary non-linearly with the visible part of the sun. For high percentages of the visible fraction of the Sun irradiance decreases rather slowly. The rate of decrease becomes faster when approaching the totality. At Kastelorizo, Nicosia and Heraklion the solar irradiance at $305 \mathrm{~nm}$ is almost 50 times weaker when the sun is visible by about $6 \%$, compared to the irradiance at non-eclipse conditions. For Kastelorizo the data for visible fraction of the sun less than $4 \%$ coverage were excluded, because of the low signal to noise ratio (less than 10).

The increased cloudiness close to the maximum and during the second phase of the eclipse at sites $1-5$ has evidently influenced the irradiance measurements (see Fig. 2, lower panel). This could be a reason for the larger differences in the measured changes with respect to the model estimates. Deviations in change of irradiance from unity at and after the end of the eclipse are attributed to changes in total ozone and in the aerosol properties relative to the period before the start of the eclipse. This effect is more evident at sites 6-8 (Fig. 2, upper panel), where the measured irradiance at $305 \mathrm{~nm}$ was $10 \%$ less in Kastelorizo and $15 \%$ more in Nicosia than the pre-eclipse values. Part of this change in irradiance at both sites could be attributed, apart from possible cloudiness, to small changes in the ozone column during the eclipse (see Sect. 6). In addition, differences in total ozone by -5 D.U. and +8 D.U. at Kastelorizo and Nicosia respectively were observed at the same time interval of the reference, cloud-free, day. Such changes in ozone during the cloud-free day used for normalization would have the same result as a change in ozone on the eclipse day.

Being only marginally affected by cloudiness, the measurements at sites 6-8 suggest that the model calculations can simulate quite well the decrease of global irradiance due to the eclipse. The agreement between measurements and modeled values at all sites is within $2 \%$ for visible parts of the sun of more than $70 \%$ and becomes worse as the eclipse progresses. The differences at Heraklion range from $10 \%$ to $55 \%$ for sun visible parts of $60 \%$ and $10 \%$, respectively. The differences at Nicosia, for the same visible sun percentages, range from $2 \%$ to $30 \%$. At Kastelorizo, the site with the highest eclipse percentage, the agreement between measurements and model estimates is within $8 \%$ for visible fraction of sun's disk equal to $10 \%$. However, close to the totality the agreement becomes worse (within 60\%) as both measurement and model uncertainties become significant.
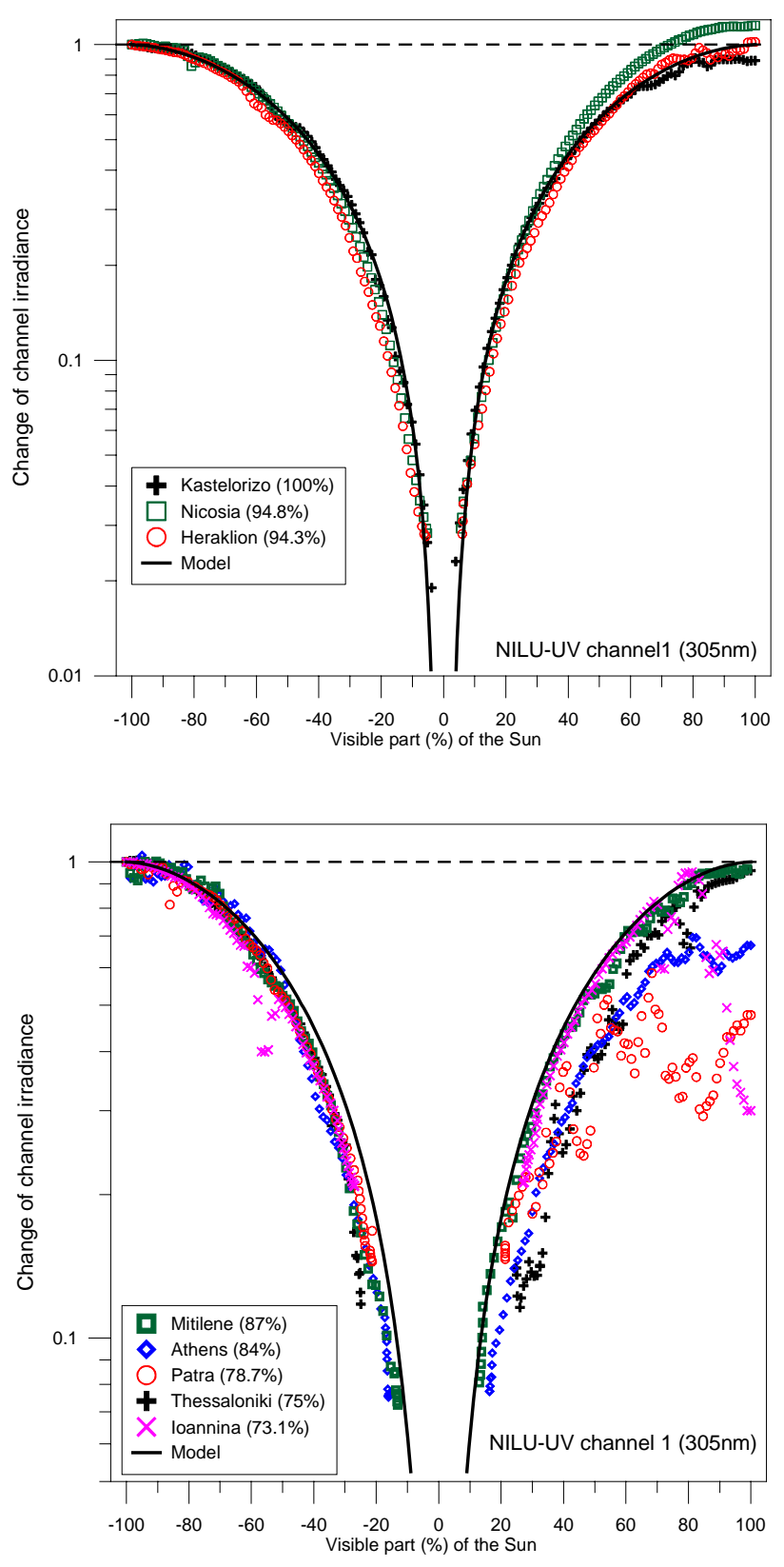

Fig. 2. Change of solar irradiance for NILU-UV channel 1 (305 nm) for sites 1-5 (upper panel) and sites 6-8 (lower panel). For each site the maximum eclipse percentage is provided.

The effect of solar eclipse on the global irradiance at 312 and $320 \mathrm{~nm}$ has been investigated too. The relative decrease of irradiance (not shown here) is of the same magnitude than for $305 \mathrm{~nm}$, while the variability of the measured data due to cloudiness is more evident, as expected from the larger contribution of direct radiation at these wavelengths. At the end of the eclipse, the deviations of the changes in solar irradiance at $312 \mathrm{~nm}$ from unity are $-3 \%$ and $7 \%$ respectively for Kastelorizo and Nicosia. The decreasing signal to noise 

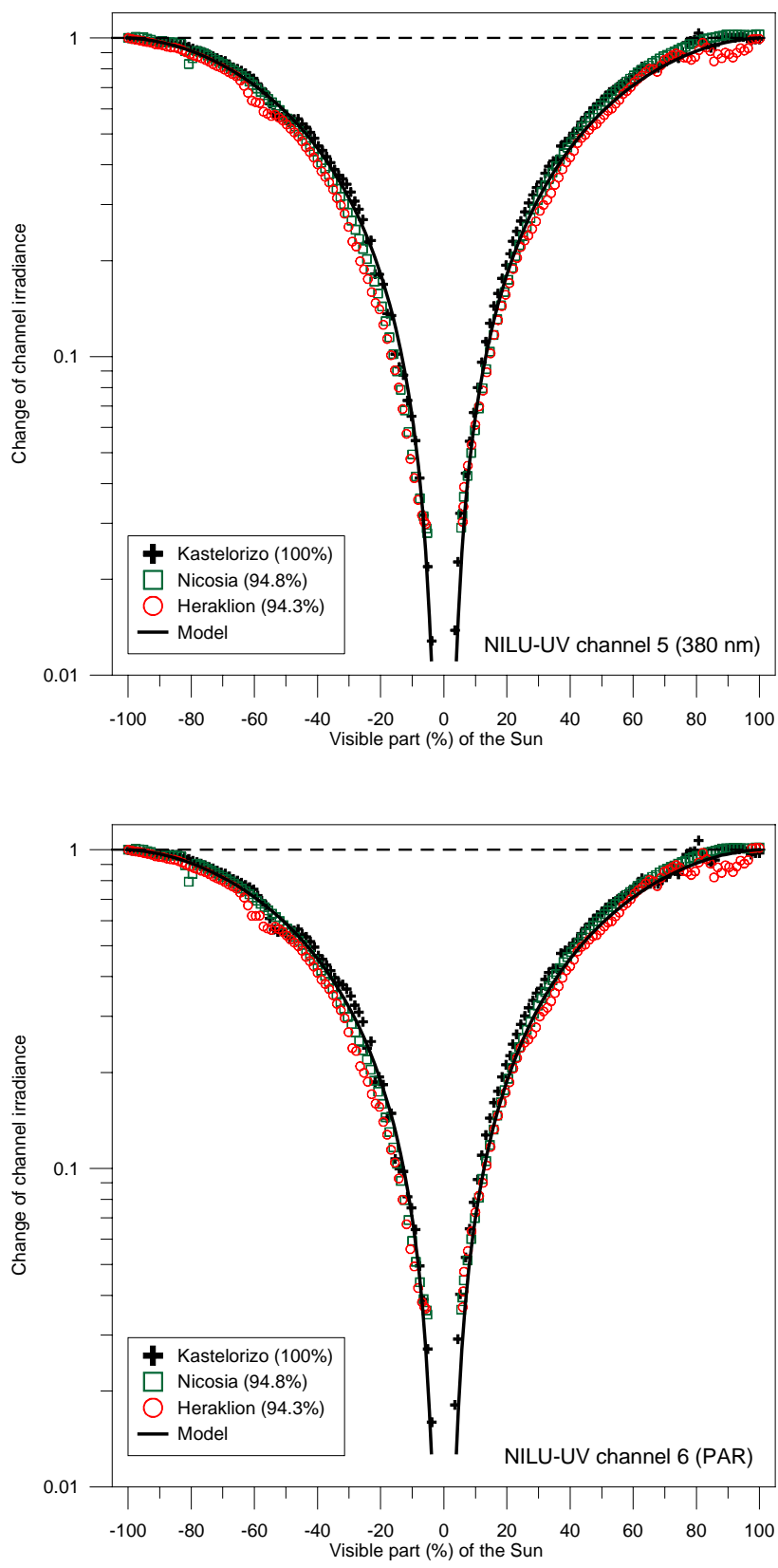

Fig. 3. Change of solar irradiance for NILU-UV channels 5 (380 nm, upper panel) and 6 (PAR, lower panel) for sites 6-8. For each site the maximum eclipse percentage is provided.

ratio at these wavelengths allows reliable measurements at Kastelorizo only up to the start of the totality.

\subsection{UV-A irradiance and PAR.}

The relative change of solar irradiance at $380 \mathrm{~nm}$ and PAR is shown only at Kastelorizo, Nicosia and Heraklion (Fig. 3) and not for the other sites, due to the increased impact of cloudiness in UVA and PAR instrument channels. The so- lar irradiance at both wavelengths is respectively 33 and 25 times weaker when the sun is visible by about $6 \%$, compared to the irradiance at non-eclipse conditions. The measured decrease on irradiance is 1.5 (at $380 \mathrm{~nm}$ ) and 2 (at PAR) times more than the corresponding value at $305 \mathrm{~nm}$. This is explained by the fact that as the eclipse progresses, the diffuse radiation originates from photons that have entered the top of the atmosphere far away from the measurement site. Since photons at shorter wavelengths are more effectively scattered than photons at longer wavelengths, they have a smaller chance of reaching the instrument.

The differences between modeled and measured irradiance at these wavelength regions are examined. For visible parts of the sun of more than $60 \%$ and apart from exceptional cases where the impact of cloudiness on measurements is obvious, the differences of irradiance at $380 \mathrm{~nm}$ is less than $3 \%$ at all sites. At Heraklion, the differences between measured and modeled values range from $5 \%$ to $80 \%$ for visible fractions of the sun equal to $60 \%$ and $10 \%$, respectively. In contrast, the half difference is observed at Nicosia at the eclipse maximum. The agreement between model estimates and measurements at Kastelorizo is within 3\% for visible parts of the sun down to $10 \%$ and increases to $20 \%$ close to totality. Differences of the same magnitude observed at the three sites for PAR.

\section{Spectral effect of the eclipse on surface global irradi- ance}

In previous paragraphs, emphasis given in the discussion of the global irradiance changes as a result of the sun coverage. However, it is well known from previous studies (e.g. Zerefos et al., 2000; Koepke et al., 2001), that during a solar eclipse the attenuation of global irradiance is wavelength dependent. In order to quantify this dependence, we calculated the change of the irradiance ratio at $305,312,340 \mathrm{~nm}$ and PAR relative to $380 \mathrm{~nm}$ during the eclipse. In this case, the effect of the sun coverage is diminished, since the ratios are formed from synchronous irradiances measurements. In contrast, the effects of cloudiness become dominant, since the influence of clouds is also wavelength dependent (Mayer et al., 1998). For this reason, the discussion is restricted to stations 6-8.

\subsection{UV-A irradiance and PAR}

Figure 4 shows the ratios of measured and modeled irradiance of $340 \mathrm{~nm}$ and PAR with respect to the irradiance at $380 \mathrm{~nm}$, as a function of the visible fraction of the sun's disk. For both wavelength regions the agreement between measurements and model calculations is within $3 \%$ for visible parts of the sun larger than $50 \%$. As the eclipse progresses, the model underestimates the spectral effect, capturing only the half of the observed change. The agreement 
between measurements at different locations is much better than with the model calculations, while the short-term variability in the measurements is mainly due to changing cloudiness. The irradiance at $340 \mathrm{~nm}$ decreases by about $10 \%$ more compared to $380 \mathrm{~nm}$, while PAR is enhanced by about $30 \%$ close to totality. The ratios after the end of the eclipse do not deviate significantly, suggesting that atmospheric parameters that may influence the irradiance at these wavelengths (e.g. aerosols, $\mathrm{NO}_{2}$ ) have remained stable.

\subsection{UV-B irradiance}

The spectral effect of the eclipse on the shorter wavelengths is shown in Fig. 5. The effect at $312 \mathrm{~nm}$ (lower panel) is similar to that reported for $340 \mathrm{~nm}$ (Fig. 4) with the exception that the ratio after the end of the eclipse is significantly different from the ratio before the eclipse, and even of different sign. This change is attributable to differences in the diurnal variation of the total ozone column between the day of the eclipse and the day of the normalization, as discussed in Sect. 4.2. The same effect is more evident at $305 \mathrm{~nm}$ (upper panel) where the ozone absorption is much stronger.

The pattern for $305 \mathrm{~nm}$ is completely different compared to the other wavelengths, since the ratio inverses at about $15 \%$ of visible part of the sun. It is not clear yet whether this behavior is caused by changes in total ozone as the eclipse progresses (will be discussed in paragraph 6) or if it is a 3-D effect from the multiple scattering of radiation under these special conditions of low direct irradiance (Emde and Mayer, 2007). It should be noted that this effect occurs only a few (less than 10) minutes before and after the totality. It is also worth noting that the same behavior is found at all three stations, hence the effect is likely to be real and not an artifact of the measurements. However, the 1-D and 3-D model calculations fail to reproduce this effect. 3-D model calculations by Emde and Mayer (2007) revealed that under such atmospheric conditions, the multiple scattering becomes important for wavelengths down to $311 \mathrm{~nm}$.

The shape of the ozone profile could also influence the global irradiance at short wavelengths, since close to the totality the contribution of the direct irradiance becomes very small. Although no ozone profile data were available, Zerefos et al. (2007) provide experimental evidence that there was an oscillation in the total ozone column. According to that study, the cooling of ozone layer in the stratosphere by the supersonic travel of the moon's shadow during an eclipse constitutes a source of gravity waves propagating both upwards and downwards, as suggested by Chimonas and Hines (1970).

\section{Total ozone from irradiance measurements}

The total ozone values, were determined by comparing a calculated and measured irradiance ratio at two channels with
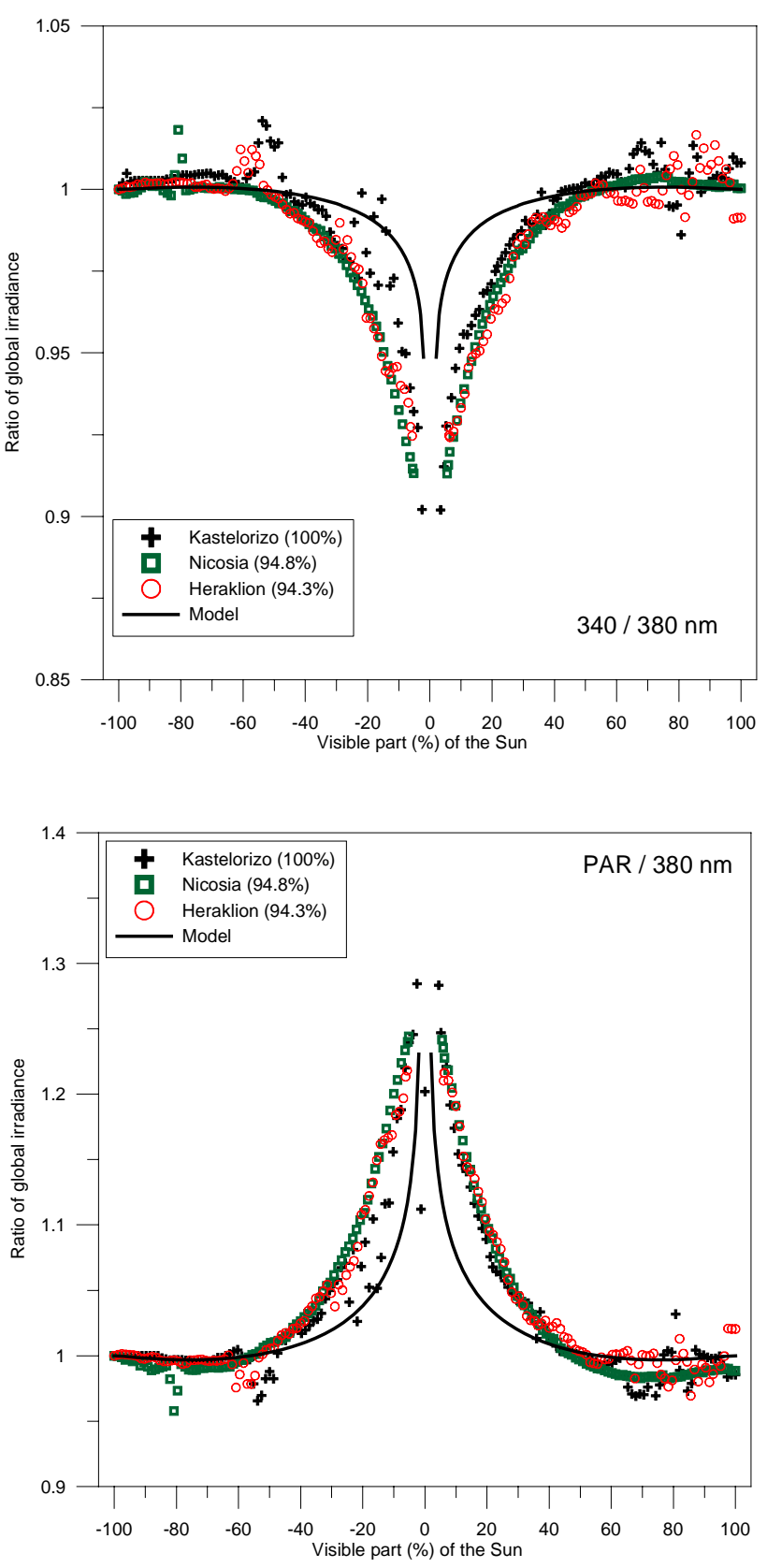

Fig. 4. The spectral difference of global irradiance attenuation at $340 \mathrm{~nm}$ (upper panel) and PAR (lower panel) relatively to measured irradiance values at $380 \mathrm{~nm}$, as derived from NILU-UV measurements and 1-D model calculations.

different ozone absorption, according to the methodology proposed by Dahlback (1996). The calculations were performed for cloud-free conditions and a look-up table was created to relate the solar zenith angle and the irradiance ratio to total ozone.

The total ozone column during the eclipse, derived from the NILU-UV radiometers using the $305 / 320 \mathrm{~nm}$ irradiance ratio, is shown in the upper panel of Fig. 6 for Kastelorizo, 

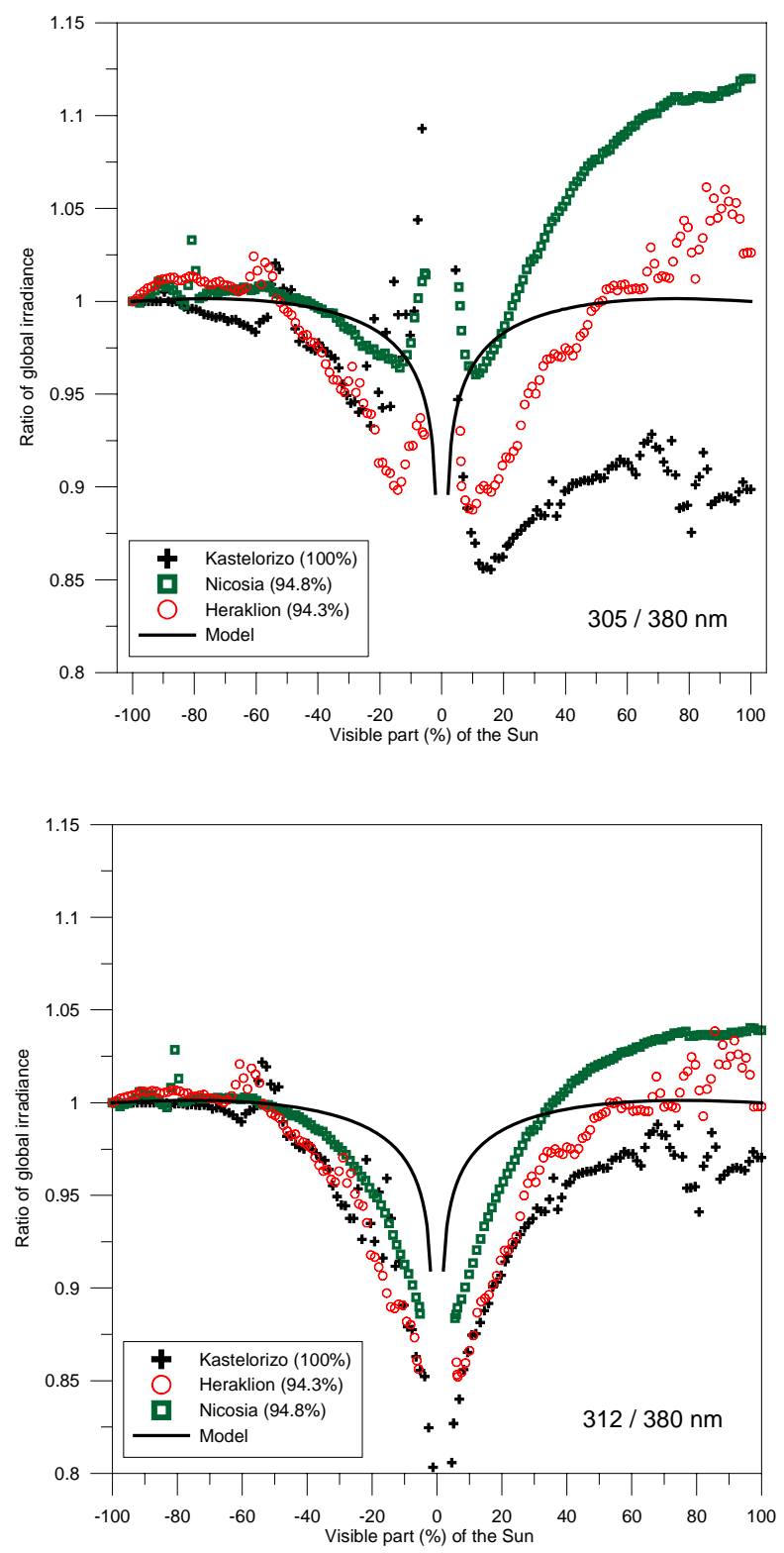

Fig. 5. Same as Fig. 4, but for $305 \mathrm{~nm}$ (upper panel) and $312 \mathrm{~nm}$ (lower panel).

Nicosia and Heraklion. The total ozone was derived for the other sites too, but they are not shown here. By the end of the eclipse the total ozone column in Patras, Athens, Mytilene and Kastelorizo has increased relative to the beginning of the eclipse respectively by about $9,24,7$ and 5 D.U., while it decreased by $\sim 4$ D.U. in Nicosia and remained almost stable in Thessaloniki and Ioannina. Similar changes were found also in the Brewer measurements at Kastellorizo and Thessaloniki (Kazadzis et al., 2007). The calculation of total ozone using the irradiance ratio of $312 / 320 \mathrm{~nm}$ has not been used here, since the influence of possible ozone variability on irradiance at $312 \mathrm{~nm}$ is less compared with the irradiance at $305 \mathrm{~nm}$.

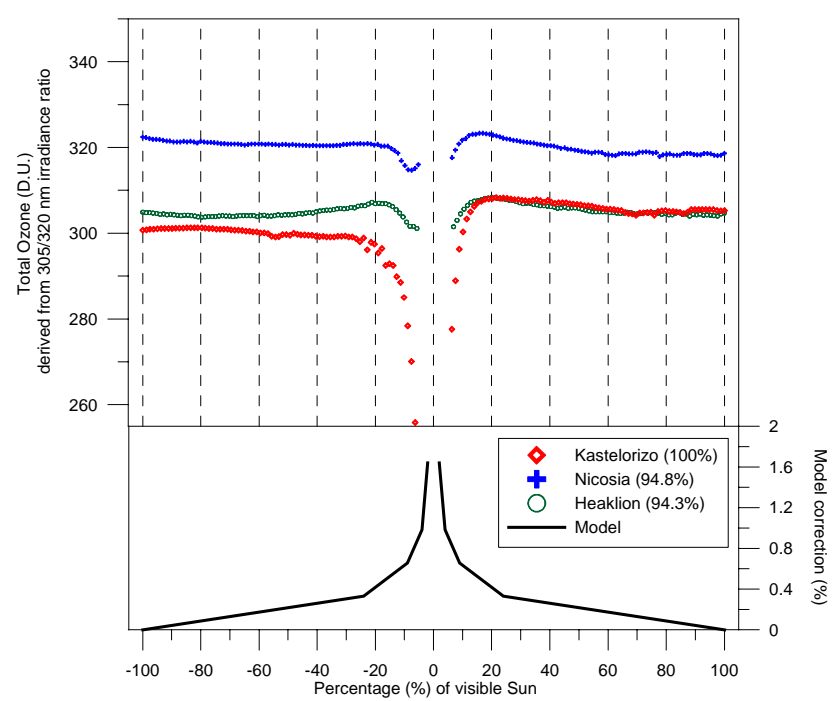

Fig. 6. Total ozone column measured by NILU-UV instruments at sites 6-8 derived from 305/320 nm irradiance ratios. Limb darkening effect on ozone calculations, derived from 1-D model results, is also presented.

The calculation of total ozone column performed also during the eclipse. In order to examine the effect of challenging radiative conditions, the measured irradiance ratio was not corrected by the limb darkening effect (it was estimated separately from 1-D model calculations) and the look-up table was not altered. As it appears from Fig. 6, the derived ozone columns from the ratio $305 / 320 \mathrm{~nm}$ show a pronounced decrease for visible fractions of the sun less than about $20 \%$, which is likely an artifact of the irradiance measurements (e.g. Zerefos et al., 2001; Kazadzis et al., 2007). Only a very small fraction of this behavior may be caused by the limb darkening effect, as it appears from the correction factor for total ozone, which is shown for the different phases of the eclipse in the lower panel of Fig. 6. This correction factor derived from 1-D model calculations of spectral irradiances taking into account the effect of the limb darkening.

Total ozone appears to increase with decreasing visible fraction of the sun between $\sim 60 \%$ and $\sim 20 \%$ up to about 5 D.U. (Fig. 6). This is evident at all sites mainly during the second phase of the eclipse and during the first phase in Heraklion. Although it could be also reasonable to attribute this effect to the spectral influence of the eclipse on the ratio $305 / 320 \mathrm{~nm}$, the correction for the total ozone, according to the formulas of Koepke et al. (2001), can explain only about half of the measured differences.

\section{Irradiance measurements and 3-D model calculations during totality}

The change in irradiance during totality, measured with the NILU-UV multi-channel radiometer at Kastelorizo, is 
compared with theoretical calculations for cloud-free skies with the MYSTIC 3-D model (Emde and Mayer, 2007). The modeled spectra in the spectral region $300-500 \mathrm{~nm}$ were weighted with the spectral responses of the NILU-UV channels, to simulate the actual irradiance measurements of the instrument. Then, the ratio of irradiance for eclipse and noneclipse conditions was calculated for every second during a period extending $5 \mathrm{~min}$ before and after the totality. All ratios were normalized with the value corresponding to the beginning of the period (i.e. $5 \mathrm{~min}$ before the eclipse maximum).

The measured and calculated reduction of irradiance at the $312 \mathrm{~nm}$ and $380 \mathrm{~nm}$ channels are presented in Fig. 7 as a function of the time difference relative to the eclipse maximum. The vertical lines close to $100 \mathrm{~s}$ correspond to the beginning and the end of the totality. For the $380 \mathrm{~nm}$ channel, the agreement between the model calculations and the measurements just before the beginning of totality is within $10 \%$. The measured irradiance decreases more rapidly during totality but the percentage difference of the two radiative quantities close to the time of the eclipse maximum is less than 5\%. After the end of totality the model overestimates the irradiance by $\sim 20 \%$. Similar results were obtained also for the $340 \mathrm{~nm}$ channel (not shown here). However, for the $312 \mathrm{~nm}$ channel the model estimates during totality are three times lower, most likely because of the increasing noise in the measurements during the totality (the measured raw counts were only $30 \%$ higher than the dark current), but also because of the possible uncertainties in determining the spectral response of this channel. Close to and after the end of totality the agreement between the modeled and the measured values is within $40 \%$.

The model uncertainty increases too at $312 \mathrm{~nm}$ due to the impact of the ozone profile. According to model sensitivity calculations, the solar irradiance at $312 \mathrm{~nm}$, using the standard tropical ozone profile instead of the mid-latitude summer profile (Anderson et al., 1986) and scaling to 300 D.U., is higher by a factor of 1.6 during totality. Finally, the hills extending above the horizon towards south and east up to an elevation of about $20^{\circ}$ can also affect the global irradiance measurements under such weak radiation conditions. The measured irradiance at $305 \mathrm{~nm}$ has reached its minimum already a few seconds before the totality, thus no results are shown for this wavelength. In addition, due to the maximum wavelength of modeled irradiance at $500 \mathrm{~nm}$, comparison with PAR cannot be performed.

\section{Conclusions}

The effect of the total solar eclipse of 29 March 2006 on UV and visible irradiance measurements from the multi-channel radiometers of the Greek UV Network have been examined.

At three network sites and for visible parts of the sun equal to $6 \%$, the solar irradiance at $305 \mathrm{~nm}$ is 50 times weaker when compared with values at non-eclipse conditions. At the same

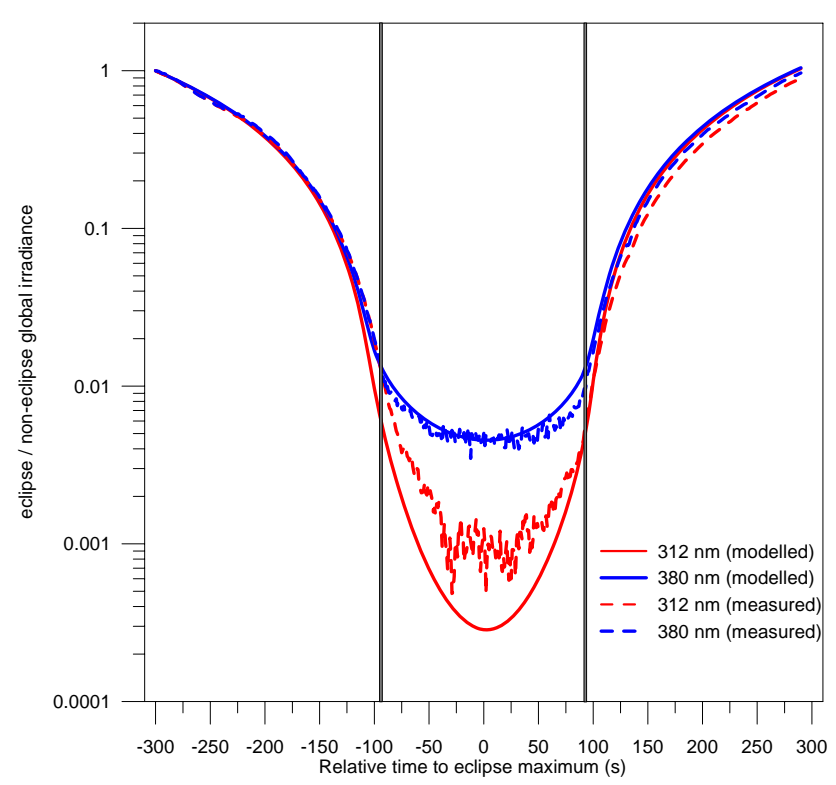

Fig. 7. The ratio of global solar irradiance between the NILU-UV instrument and MYSTIC 3-D model calculations during the eclipse at Kastelorizo. The time $\mathrm{t}=0$ denotes the maximum of the eclipse and the grey lines correspond to the beginning and the end of the totality.

time, the irradiance at UVA and visible spectral regions was respectively 33 and 25 times weaker. The comparison of measured irradiance with 1-D model calculations (accounting for the limb darkening effect) reveals differences of $3 \%$ for visible sun's fractions of more than $70 \%$, but becomes worse as the eclipse progresses.

The effect of the eclipse on surface irradiance has spectral characteristics. Although the shorter wavelengths are generally influenced more, when the visible fraction of the sun is less than $15 \%$ the picture reverses for the shortest wavelength $(305 \mathrm{~nm})$ which decreases with slower rates compared to the longer wavelengths as the eclipse approaches its maximum. The 1-D ad 3-D models cannot simulate this observation and no ozone profile measurements were available. So, the interpretation of this observation remains a challenge for a future research.

Total ozone derived from irradiance measurements at 305 and $320 \mathrm{~nm}$ shows a behavior similar to that reported in the past for other eclipses. It shows a slight increase when the visible part of the sun is more than $20 \%$ and decreases significantly as the eclipse progresses.

The reduction of irradiance during the totality as predicted by a 3-D model is compared with measurements for the first time. The agreement between model and measurements during totality in the UV-A region is within 5\% at the time of the eclipse maximum, but worsens significantly in the UV-B. 
Acknowledgements. The authors are indebted to scientists that help in maintaining the instruments of the Greek UV monitoring network: C. Feidas and S. Kolios, University of Aegean, Mytilene; I. Pnevmatikos, University of Ioannina; K. Eleftheratos, University of Athens; A. A. Argiriou and S. Lykoudis, University of Patras; N. Michalopoulos and M. Kanakidou, University of Crete, Heraklion; O. Poulida, Frederik Institute of Technology, Nicosia, Cyprus.

Edited by: N. Mihalopoulos

\section{References}

Anderson, G., Clough, S., Kneizys, F., Chetwynd, J., and Shettle, E.: AFGL Atmospheric Constituent Profiles (0-120 km), Tech. Rep. AFGL-TR-86-0110, AFGL (OPI), Hanscom AFB, MA 01736, 1986.

Bernhard, G., Booth, C. R., and Ehramjian, J. C.: Real-time ultraviolet and column ozone from multichannel ultraviolet radiometers deployed in the National Science Foundation's ultraviolet monitoring network, Opt. Eng., 44(4), 041011, 2005.

Bojkov, R. D: The ozone variations during the solar eclipse of May 20 1966, Tellus, 20, 417-421, 1968.

Chakrabarty, D. K, Shah, N. C., and Pandya, K. V.: Fluctuation in ozone column over Ahmedabad during the solar eclipse of 24 October 1995, Geophys. Res. Lett., 24, 3001-3003, 1997.

Chakrabarty, D. K., Peshin, S. K., Srivastav, S. K., Shah, N. C., and Pandya, K. V.: Further evidence of total ozone variation during the solar eclipse of 1995, J. Geophys. Res., 106, D3, 3213-3218, 2001.

Chimonas, G. and Hines, C. O.: Atmospheric gravity waves induced by a solar eclipse, J. Geophys. Res., 75, p. 875, 1970.

Dahlback, A.: Measurements of biologically effective UV doses, total ozone abundances, and cloud effects with multichannel, moderate bandwidth filter instruments, Appl. Opt., 35(33), 65146521, 1996.

Dahlback, A. and Stamnes, K.: A new spherical model for computing the radiation field available for photolysis and heating at twilight, Planet. Space Sci., 39, 671-683, 1991.

Emde, C. and Mayer, B.: Simulation of solar radiation during a total eclipse: a challenge for radiative transfer, Atmos. Chem. Phys., 7, 2259-2270, 2007,

http://www.atmos-chem-phys.net/7/2259/2007/.

Espenak, F. and Anderson, J.: Total solar eclipse of 2006 March 29, Tech. Rep., Goddard Space Flight Centre, 2004.

Fernandez, W., Castro, V., Wright, J., Hidalgo, H., and Saenz, A.: Changes in solar irradiance and atmospheric turbidity in Costa Rica during the total solar eclipse of July 11, 1991, Earth Moon Planets, 63, 119-132, 1993.

Høiskar, B., Haugen, R., Danielsen, T., Kylling, A., Edvardsen, K., Dahlback, A., Johnsen, B., Blumthaler, M., and Schreder, J.: Multichannel moderate-bandwidth filter instrument for measurement of the ozone-column amount, cloud transmittance, and ultraviolet dose rates, Appl. Opt., 42(18), 3472-3479, 2003.

Kalivitis, N., Gerasopoulos, E., Vrekoussis, M., Kouvarakis, G., Kubilay, N., Hatzianastassiou, N., Vardavas, I., and Mihalopoulos, N.: Dust transport over the eastern Mediterranean derived from Total Ozone Mapping Spectrometer, Aerosol Robotic Network, and surface measurements, J. Geophys. Res., 112, D03202, doi:10.1029/2006JD007510, 2007.
Kazadzis, S., Bais, A., Amiridis, V., Balis, D., Meleti, C., Kouremeti, N., Zerefos, C. S., Rapsomanikis, S., Petrakakis, M., Kelesis, A., Tzoumaka, P., and Kelektsoglou, K.: Nine years of UV aerosol optical depth measurements at Thessaloniki, Greece, Atmos. Chem. Phys., 7, 2091-2101, 2007, http://www.atmos-chem-phys.net/7/2091/2007/.

Kazadzis, S., Bais, A., Blumthaler, M., Webb, A., Kouremeti, N., Kift, R., Schallhart, B., and Kazantzidis, A.: Effects of total solar eclipse of 29 March 2006 on surface radiation, Atmos. Chem. Phys. Discuss., 7, 9235-9258, 2007, http://www.atmos-chem-phys-discuss.net/7/9235/2007/.

Kazantzidis, A., Bais, A. F., Balis, D. S., Kosmidis, E., and Zerefos, C. S.: Sensitivity of solar UV radiation to ozone and temperature profiles at Thessaloniki $\left(40.5^{\circ} \mathrm{N}, 23^{\circ} \mathrm{E}\right)$, Greece, J. Atmos. Sol.Terr. Phy., 67, 1321-1330, 2005.

Kazantzidis, A., Bais, A. F., Topaloglou, C., Garane, K., Zempila, M., Meleti, C., and Zerefos, C. S.: Quality assurance of the Greek UV Network: preliminary results from the pilot phase operation, SPIE Europe Remote Sensing of Clouds and the Atmosphere XI, 6362, 636229, 2006.

Köpke, P., Reuder, J., and Schween, J.: Spectral variation of the solar radiation during an eclipse, Meteorol. Z., 10, 179-186, 2001.

Lapeta, B., Engelsen, O., Litynska, Z., Kois, B., and Kylling, A.: Sensitivity of surface UV radiation and ozone column retrieval to ozone and temperature profiles, J. Geophys. Res., 105, 50015007, 2000.

Mariolopoulos, E., Zerefos, C. S., Bloutsos, A., and Repapis, C.: Ozone and temperature balloon measurements during the annular solar eclipse of 29 April 1976, Proc. Acad. Athens, 51, 636-645, 1977.

Mayer, B., Kylling, A., Madronich, S., and Seckmeyer, G.: Enhanced absorption of UV radiation due to multiple scattering in clouds: experimental evidence and theoretical explanation, J. Geophys. Res., 103, 31 241-31 254, 1998.

Mayer, B. and Kylling, A.: Technical Note: The libRadtran software package for radiative transfer calculations: Description and examples of use, Atmos. Chem. Phys., 5, 1855-1877, 2005, http://www.atmos-chem-phys.net/5/1855/2005/.

Mikhalev, A. V., Chernigovskaya, M. A., Beletsky, A. B., Kazimirovsky, E. S., and Pirog, O. M.: Variations of the groundmeasured solar ultraviolet radiation during the solar eclipse on 9 March, Adv. Space Res., 1999, 24, 657, 1997.

Mims, F. M. and Mims, E. R.: Fluctuations in column ozone during the total solar eclipse of July 11, 1991, Geophys. Res. Lett., 20, 367-370, 1993.

Sharp, W. E., Silverman, S. M., and Lloyd, J. W. F.: Summary of sky brightness measurements during eclipses of the sun, Appl. Opt., 10, 1207-1210, 1971.

Shaw, G. E.: Sky radiance during a total solar eclipse: a theoretical model, Appl. Opt., 17, 272-278, 1978.

Shettle, E.: Models of aerosols, clouds and precipitation for atmospheric propagation studies, in: Atmospheric propagation in the uv, visible, ir and mm-region and related system aspects, no. 454 in AGARD Conference Proceedings, 1989.

Silverman, S. M. and Mullen, E. G.: Sky brightness during eclipses: a review, Appl. Opt., 14, 2838-2843, 1975.

van Hoosier, M. E.: Solar ultraviolet spectral irradiance data with increased wavelength and irradiance accuracy, SPIE proceedings, 2831, 57-64, 1996. 
van Weele, M., Martin, T. J., Blumthaler, M., Brogniez, C., den Outer, P. N., Engelsen, O., Lenoble, J., Mayer, B., Pfister, G., Ruggaber, A., Walravens, B., Weihs, P., Gardiner, B. G., Gillotay, D., Haferl, D., Kylling, A., Seckmeyer, G., and Wauben, W. M. F.: From model intercomparison toward benchmark UV spectra for six real atmospheric cases, J. Geophys. Res., 105, 49154925, 2000.

Winkler, P., Kaminski, U., Koehler, U., Riedl, J., Schroers, H., and Anwender, D.: Development of meteorological parameters and total ozone during total eclipse of 11 August 1999, Meteorol. Z., 10, 193-199, 2000.

Zerefos, C. S., Balis, D. S., Meleti, C., Bais, A. F., Tourpali, K., Vanicek, K., Cappelani, F., Kohler, U., Tiziano, C., Stubi, R., Formenti, P., and Andreae, A.: Changes in environmental parameters during the solar eclipse of August 11, 1999, over Europe. Effects on Surface W Solar h-radiance and Total Ozone., J. Geophys. Res., 105, 26463-26473, 2000.
Zerefos, C. S., Balis, D. S, Zanis, P., Meleti, C., Bais, A. F., Tourpali, K., Melas, D., Ziomas, I., Galani, E., Kourtidis, K., Papayannis, A., and Gogosheva, Z.: Changes in surface UV solar irradiance and ozone over the Balkans during the eclipse of August 11, 1999, Adv. Space Res., 27, 1955-1963, 2001.

Zerefos, C. S., Gerasopoulos, E., Tsagouri, I., Psiloglou, B. E., Belehaki, A., Herekakis, T., Bais, A., Kazadzis, S., Eleftheratos, C., Kalivitis, N., and Mihalopoulos, N.: Evidence of gravity waves into the atmosphere during the March 2006 total solar eclipse, Atmos. Chem. Phys., 7, 4943-4951, 2007, http://www.atmos-chem-phys.net/7/4943/2007/. 